\title{
Presenting a Model of System Dynamics for Air Pollution Caused by Ceramic Tile Industry in Yazd
}

\author{
Elham Mofattehzadeh * \\ MA, Department of Management, Yazd Branch, \\ Islamic Azad University, Yazd, Iran \\ Abolfazl Sadeghian \\ Assistant Professor and Faculty Member,Department of Management, \\ Yazd Branch, Islamic Azad University, Yazd, Iran \\ *Corresponding Author: Elhamm@live.com
}

\begin{abstract}
Air pollution is undoubtedly one of the most important environmental issues in the world and especially in major cities. The need to investigate this issue is apparent given the importance of the problem of air pollution and its impact on the health of residents. The problem of air pollution in metropolises is the result of the combination of several factors, one of the most important onebeing the industrial sector and, among them, polluting industries including ceramic tile industry. Using a dynamic system modeling approach and selecting Yazd, Iran as a case study and alsoconsidering the inherent complexity of each of the factorsthat makes it impossible to be analyzed using conventional tools of mathematical modeling, this study tries to presenta pollution subsystem of ceramic tile industry in order to analyze the problem of air pollution of Yazd. This simulation is carried out over a six-year period using Vensim software, and represents a long-term vision. This model and the simulation accompanying it can be used as an applied decision support system for ceramic tile industry decision-makers and environmentalists in order to make the best possible decisions based on the circumstances of their organization or factory.
\end{abstract}

Keywords, Air pollution, Ceramic tile industry, Dynamic systems, Vensim software.

\section{Introduction}

In recent years, due to the increasing urbanization, traffic, and industrial development in the margins of big cities, air pollution of cities has become a major challenge in urban management. Air pollution has been with human beings since the first fire was lit; however, in different times, different aspects of pollution have been given importance. The origin of air pollution in the early years of the industrial revolution was mainly coal fuel and industry; in the twentieth and first and twenty-first century, however, urban transport was responsible for air pollution. Fossil fuels in the transport industry, on the one hand, and industrial processes with the consumption of raw materials and manufactured products, on the one hand, are major contributors to handmade pollutions [1].

Different approaches have been applied to investigate and analyze the air pollution trends, especially in metropolises. Since this topic is categorized within the field of socioeconomic systems where many factors are involved and their effects are usually non-linear and complex, it can be said that the city's air quality management is in the domain of complex systems. Meanwhile, the need for tools to simulate such a system and assess different strategies influencing it is of crucial importance. In this paper, system dynamicsare used to model the factors affecting the city air pollution and assess the outcomes of implementing various strategies of urban management and their effect on changing air pollution level. Yazd, as a metropolis that suffers from the increasing level of air pollution, is selected for the case study. In addition, the effects of different strategies of reducing the level of some air pollutants caused by the ceramic tile factories is investigated and analyzed using the proposed model. In system dynamics, feedback loops, endogenous and exogenous variables, and system equations are used to model complex phenomena. Feedback loops are defined as closed chains of causal relationships between variables. Variables are generally divided into three categories: (1) state variables, that are the location of accumulation of flows over time, (2) rate variables, that represent input or output flows to state variables at any period of time, and (3) slack variables,by which feedback loops are completed. System modeling throughsystem dynamicstools can effectively analyze complex socioeconomic problems. Developing a mathematical model out of a complex system often leads to the creation of a nonlinear model with a large number of variables and constraints, which makes it impossible to solve the model. However, due to the use of causal loops, system dynamics can simulate the complexity between variables as well as their impact on each other in different time periods, and thus it can be an efficient tool for studying systems with the complexity of 
high relationships for longtime horizon. This feature makes system dynamics superior to other modeling tools used forstudying complex systems. In this paper, a model is developed based on causalloops to study the air pollution problem in Yazd; based on that, the effective factors are identified and the system behavior is simulated as a result of different control policies. In order to simulate the behavior of this system, influential subsystems are identified, then the main variables are determined, and finally the mathematical equations are extracted based on historical data. Within the framework of the complex causal relationships of this system, the impact of various applicable policies on reducing air pollution in Yazd can be assessed. The data required to create and simulate such a system re extracted from a variety of sources, such as environmental data, industrial data, and so on.

\section{Literature review}

Wang et al. (2012) developed a system dynamics model for eliminating the pollution of surface water and wetlands [2]. Using system dynamics approach, Trappeyet al. (2012) studied the emission of greenhouse gases and pollution causedby them in Taiwan. They proposed scenarios based on supplying electric motorcycles and limiting the supply of fossil fuel-powered motorcycles [3]. Yu and Wei (2012) developed a combined model of system dynamics, called genetic algorithms, to study the pollution caused by coal production in China. They used a genetic algorithm to adjust the parameters of the system dynamics model [4]. Fartoukzadeh and Rajabi Nahouji (2012) examined the urban transportation in Tehran in a 15-year horizon; they considered air pollution as a slack variable affecting traffic congestion. Their proposed policies to control traffic volume and thereby reduce Tehran's air pollution, decrease travel demand through the development of e-government and optimal city design, reduce the attractiveness of using private cars, and increase the attractiveness of public transportation systems by reducing travel time [5].

In their study, Rayoufi et al. (2017) used linear regression analysis for the development of the relationship between the values of Aerosol Optical Depth (AOD) measured by Moderate Resolution Imaging Spectroradiometer (MODIS) and the daily air pollution data (CO, O3, NO2, SO2, PM2. 5) in 6 consecutive years (2013-2017), which were collected at 22 stations located throughout Tehran. The correlation matrix between AOD values and air pollution parameters demonstrated that a significant relation existed at the level of 0.001 with R2 values from 0.631 to 0.776 for O3 and NO2, respectively. The linear regression between AOD and each pollution parameter was developed separately and the contamination map was computed for $\mathrm{CO}, \mathrm{O} 3$, NO2, and PM2.5 parameters at the area under investigation for the period between 2013 and 2017. The spatial distribution map of the mentioned gases showed that NO2 and CO exceeded their standard levels at the study area during the studied period [6].

The study conducted by Davar Panah et al. (2017) aimed atanalyzing and evaluating the principles and legal texts of Iran regarding soil, climate, and air pollution, and tried to provide legal solutions to the reduction of pollution or prevention of its emission sources. The study applied a library method based on taking notes of written and online sources. The investigation also adopted a descriptive-analytical approach [7].

\section{Definition of the problem}

The rapid growth of population, rural migration, plant expansion, vehicle density, and natural conditions are among the factors that have led to increased energy consumption [8]. The effects of this on air pollution, which have made metropolises the most polluted cities in the world, have contributed to a decline in the quality of life in these big cities [9]. Apart from the deaths caused by extreme air pollution in the short run, it is getting more and more clear that a little air pollution can have detrimental effects on human beings in the long run. Although different initiativeshave been proposed by various environmentally-friendly institutions and organizations for reducing air pollution, they not only have not solved this problem in practice, but have increased the amount and intensity of it. Given what was discussed above, it can be concluded that, without taking into account all the influential factors of system dynamics and their effects on each other,most of these initiatives have exacerbated the problem. Thus, this study is conducted to solve the problem using system dynamics to accurately and properly consider the dynamics and the impact of the related factors on the issue, so that some practical and appropriate solutions can beproposedforsolving the problem.

\subsection{Research objectives}

This research aims at identifying the indicators and factors of Yazd'sair pollution and at proposinga system dynamics model for analyzing the pollution caused by ceramic tile industry.

\subsection{Research questions}

What are the indicators and factors affecting air pollution?

How is the dynamic model for removing air pollutants from ceramic tile industry developed? 


\section{Research method}

In this research, in order to obtain theoretical data, various methods including library studies, reference to scientific documents and resources, and computer searches indatabases and websites were used. In addition, to obtain model data, company documentations and interviews with experts were used. Also, experts' opinion was used to determine the relationships between some variables.The variables, the collected data, and the relationships between variables were then entered into Vensim software. Using the software, simulation model and sensitivity analysis on the model were done.

\section{System dynamics}

System dynamics is a perspective and a set of conceptual tools that enables us to understand the structure and dynamics of complex systems. In system dynamics, we learn from our long-term side effects of our decisions, speed up our learning, understand complex systems, and design structures and strategies for more success. The purpose of the systematic thinking and system dynamics modeling is to improve the understandingthrough the identification of the organization's performance using its internal structure and operational policies involving its customers, competitors, and suppliers, and then to design and use highly influential leverage policies that lead to the organization's success [10]. System dynamics was first developed in the late 1950s by a group of researchers led by Forrester at the MIT (Massachusetts Institute of Technology). Forrester first used a system dynamicstechnique to model and simulate a long-term decision-making method in the dynamics of industrial management. The system dynamics technique "assumes that things are interconnected in complex patterns, that the world is made up of rates, levels and feedback loops, that information flows are intrinsically different from [and more important than] physical flows, that non-linearities and delays are important elements in systems" (Lane \& Oliva, 1998). One of the objectives of system dynamics modeling is examining different potential policies to improve system performance. Among these policies, the one that gives the best results is chosen to run on the system. This science is used to understand and analyze the behavior and action of the system components. The ability of this science is to the extent that it can be used to model various simple and complex problems, to analyze the change caused by the interactionsbetween the variables, and to identify their future behaviors in different time periods. System dynamics is a method of studying and managing complex systems with feedback. These systems can be found in various fields such as business, economics, environment, energy management, urban issues, and other social and human areas. Due to the interactions between different sectors of a system, individuals are required to understand system behavior through systematic attitude. This understanding can only be achieved by studying and recognizing all the components and their relationship within a system [11]. The system dynamics approach is mainly used in cases where the behavior of the phenomenon is caused by the natural dynamics and interactions of the intrinsic variables of the system. Assuming that the system functions normally,system dynamics can be used to analyze the system.

\subsection{Variables}

Table 1 showsthe Summary of the explanation and interpretation of simulation model elements:

Table 1 Summary of the explanation and interpretation of simulation model elements

\begin{tabular}{|c|c|l|}
\hline No. & Model elements & \multicolumn{1}{|c|}{ Description } \\
\hline 1 & Air pollution & $\begin{array}{l}\text { It is defined as any substancepolluting the air or a combination of } \\
\text { these pollutants, including any physical, chemical, biological, and } \\
\text { radioactive substances entering the air. }\end{array}$ \\
\hline 2 & Green manufacturing & $\begin{array}{l}\text { This concept refers to the costs spent for protecting the environment } \\
\text { and natural resources. }\end{array}$ \\
\hline 3 & Air treatment filter & $\begin{array}{l}\text { It is a device used to collect suspended particles that are dispersed in } \\
\text { the air in different stages of production. The filter separatesthe } \\
\text { particles from the air and returns the air free from contamination to } \\
\text { the environment. }\end{array}$ \\
\hline 5 & Technology & $\begin{array}{l}\text { They are sets of guidelines implemented by a group of institutions, } \\
\text { that actas a mediator in social links between people. }\end{array}$ \\
\hline 6 & Transportation & $\begin{array}{l}\text { It is a set of techniques, skills, methods, and processes used to } \\
\text { produce goods or services. }\end{array}$ \\
\hline 7 & Distance & $\begin{array}{l}\text { It generally refers to the transport of humans, animals, or goods. In } \\
\text { this study, it refers to the extent of carrying materialsorproduced } \\
\text { goods. }\end{array}$ \\
\hline
\end{tabular}




\begin{tabular}{|c|c|l|}
\hline 8 & Capacity production & $\begin{array}{l}\text { It refers to the amount or extent the plant is capable of producing } \\
\text { something. }\end{array}$ \\
\hline 9 & Demand & It is the desire or ability of an individual to get goods or services. \\
\hline 10 & $\begin{array}{c}\text { Political and economic } \\
\text { performance of the } \\
\text { government }\end{array}$ & $\begin{array}{l}\text { It refers to the measures such as planning, budgeting, and controlling } \\
\text { the things that should be mainly done by the government. }\end{array}$ \\
\hline
\end{tabular}

\subsection{Accumulation and flow graph}

This graph shows the interaction between the variables of a system and can be the basis for developing a quantitative model. In plotting the flow graph, familiarity with the two concepts of accumulation and flow is essential. In each system, the amount of some variables increases or decreases. These variables are called accumulationvariables. The rate of the increase or decrease of these variables is called flow. The flow graph of a system can be extracted using the literature review, the opinion of the experts, and the information obtained from sampling over the desired time period. During the construction of this graph, quantitative formulas, qualitative equations, and numerical functions are used [10, 12]. The causal graphs may be easily used improperly due to some constraints. One of the main constraints of causal graphs is their inability to display the structure of the flow and level of the systems. Flow feedback and level are the two key concepts in the dynamical system theory. Levels are system accumulations. They represent the level of the system and the information obtained from them is the basis of making decisions. Levels lead to stagnation in the system. In addition, with the accumulation of the differences in inputs and outputs, the levelscause delay in the system [10].The flow graphs of the model are presented in the following figure:

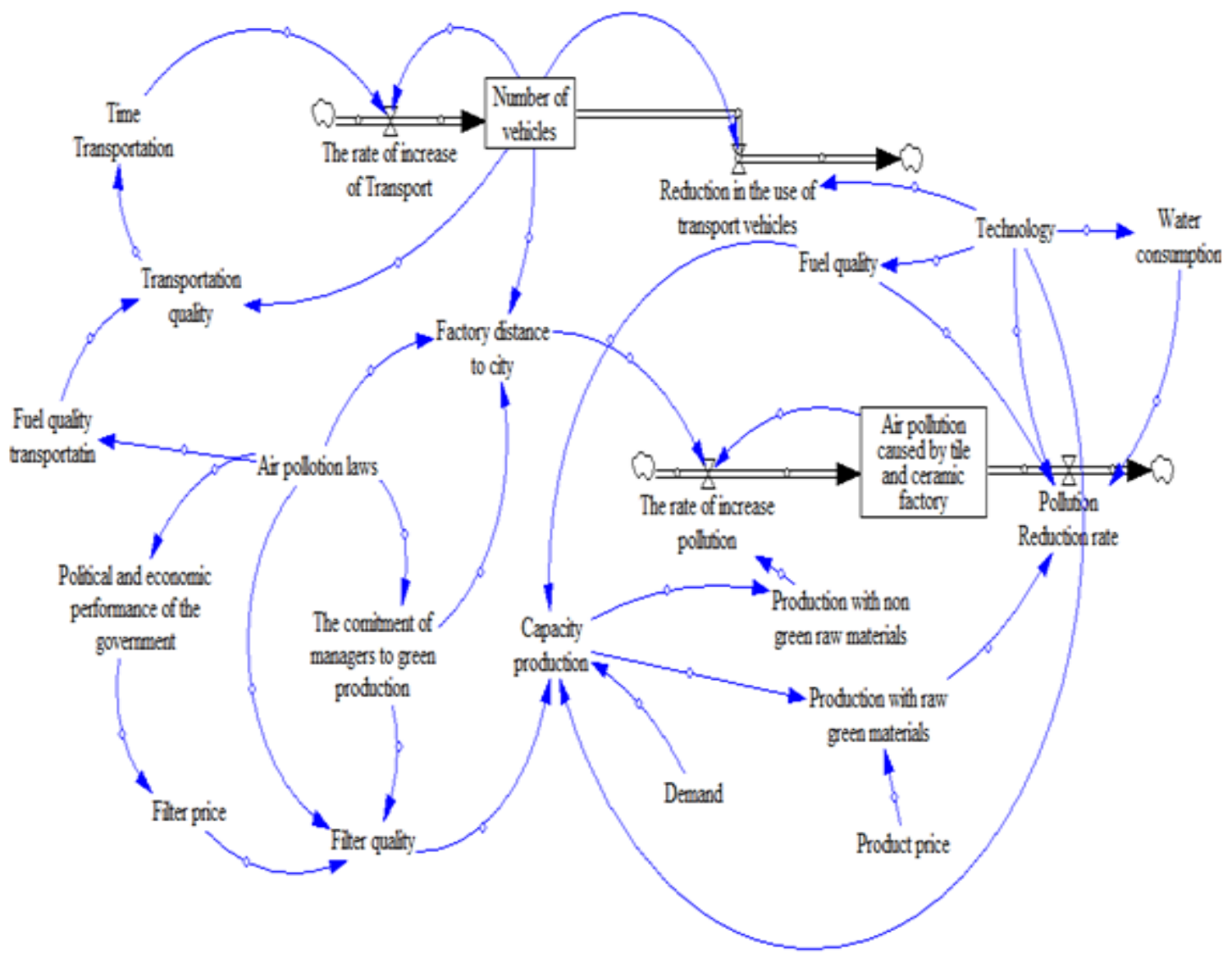

Fig. 1. Flow graph

\subsection{Simulations and basic findings of the model}

Sterman (????) argues that mathematical simulation derived from dynamic modeling is a powerful tool for learning development. Through multiple feedbacks that occur in the modeling process, a learning context is made for the modeler. Although the dynamic technique of a system provides theoretical basis for modeling complex systems in a learner context, it can only become an effective tool once it can be used to examine different processes andsystematically evaluate different scenarios [10]. After analyzing and understanding causal loop's behavior, testing the whole model will be easier. Testing system dynamics model should be done 
through a coherent and targeted process. A detailed study of various simulation experiments helps to gain insight into the real problem and the function of the systems involved in the problem, which is the very fundamental objective of the modeling of system dynamics; the perception of the model's behavior will consequently lead to understanding the behavior of real systems [12]. The simulation can be seen in Fig.2, which shows that the air pollution in Yazd decreased steadily in the first year, which is due to the decrease in the production rate of that year.In the second year,the air pollution increased at a lower rate due to the increased production. However, it dramatically increased in the third year, which can be explained by the lack of strict rules on the application of filters and quality of raw materials. Yet, from the third year to the sixth, the air pollution decreased slightly due to reduction of production and better implementation of rules corresponding to air pollution.

Air pollution caused by tile and ceramic factory

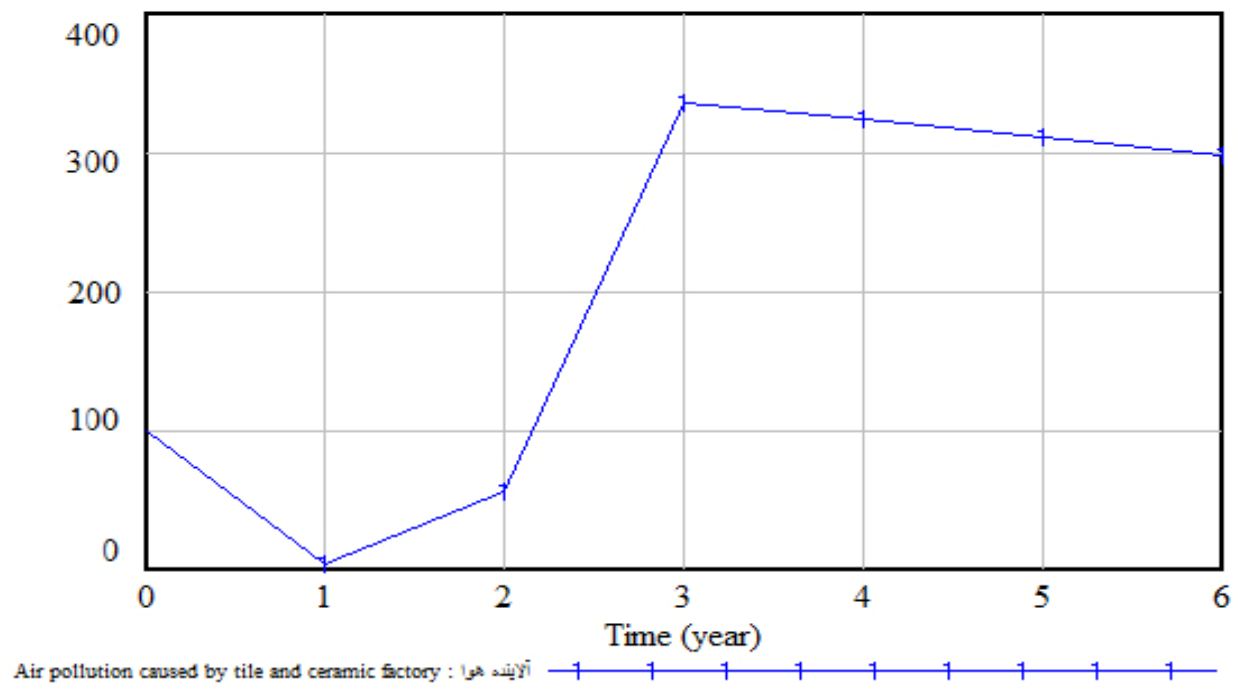

Fig. 2. Air pollution caused by ceramic tile industry

\subsection{Sensitivity analysis}

An important point that must be taken into account while using system thinking and Vensim software is that we should know the effect of changing each of the variables on the main variable, which, in this study, is the air pollution caused by the ceramic tile industry. This sensitivity analysis is a great help in decision making of the managers of ceramic tile factories as well as environmental organizations. Some examples of this sensitivity analysis are as follows:

If we increase the effect of air pollution laws variable by $20 \%$, its effect on air pollution would be what is demonstrated in Fig. 3. As shown below, the level of air pollution reduces significantly.

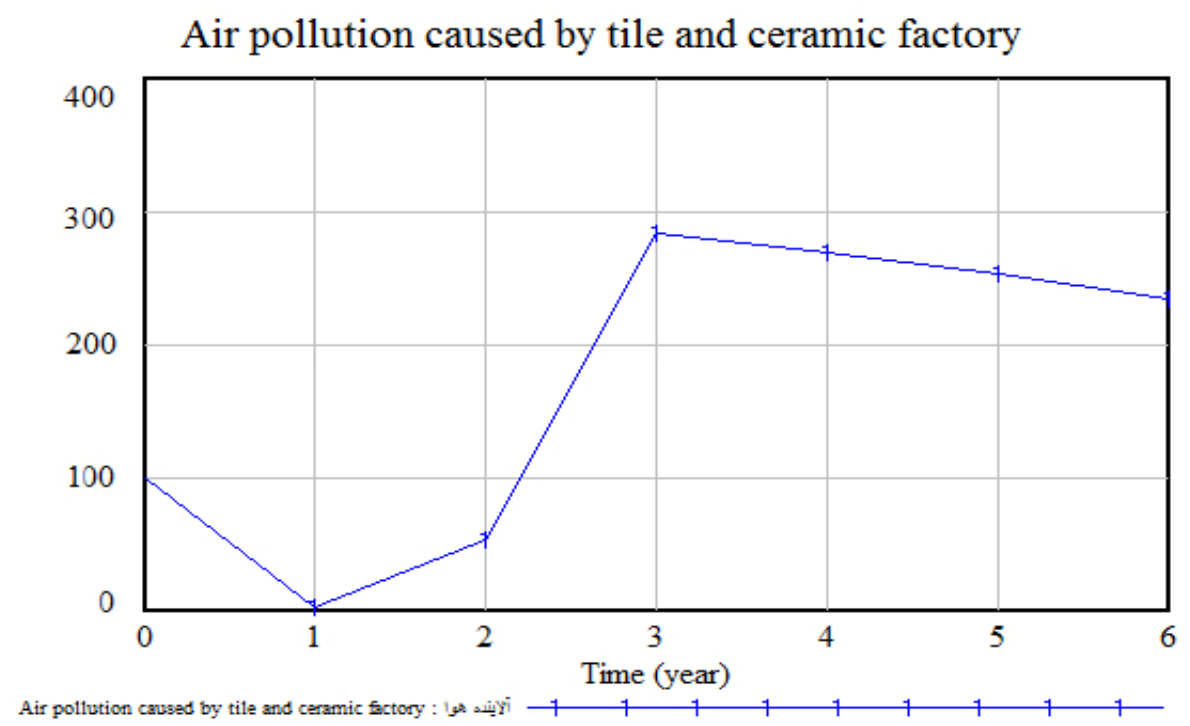

Fig.3. A $20 \%$ increase in the implementation of laws corresponding to air pollution 
If the distance from the factory to the city is increased by $20 \%$, the change in the air pollution caused by the ceramic tile industry would be what is demonstrated in Fig. 4. As shown in the figure, a $20 \%$ increase in the distance from the factory to the city will result in a significant reduction in air pollution in the last year.

\subsection{Analysis and improvement of policies}

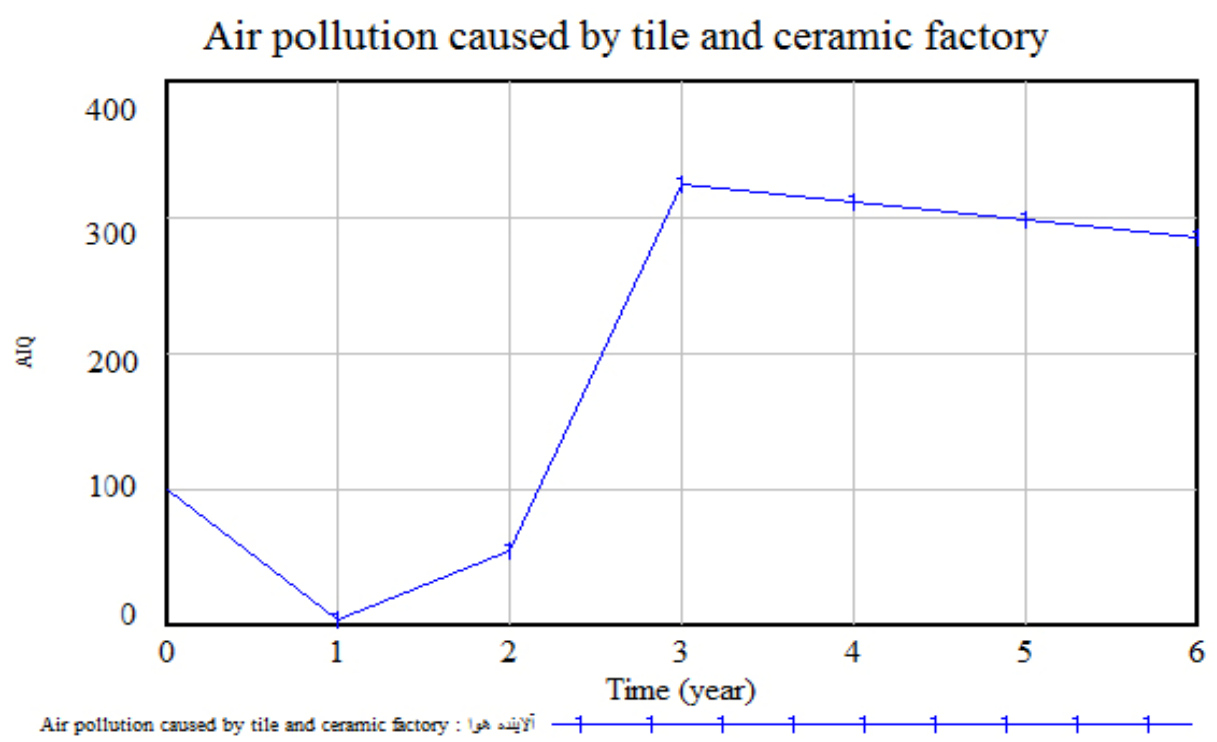

Fig. 4. A $20 \%$ increase in the distance from factory to the city of Yazd

The final acceptable and validmodelis the one that uses parametric and structural changes as alternative policies. Thus, in order to identify leverage points for the better control of the system, it is necessary to identify sensitive policy parameters. Structural changes can be done by adding policy parameters, changing policy parameters in the middle of the run, adding new feedback loops, etc. [12]. The results of the policy analysis obtained by parametric changes help the design of improved policies for the system in the form of selecting proper values for policy parameters [12].Given what was discussed above, it is possible to reduce the air pollution caused by ceramic tile factories in Yazd using some scenarios mentioned below:

1. Increasing air pollution-related laws, such as increasing the distance from factory to city and addressing the quality of the filters used, significantly contributes to the reduction of the air pollution caused bythese factories.

2. Using appropriate fuels and green raw materials in the production of goods as well as not using worn out equipment significantly leads to the reduction of air pollution.

3. Enhancing e-commerce, which eliminates the need for transportation, reduces the use of personal transportation, improves the quality of the transportation system, and consequently results in reducing air pollution.

\section{Conclusion}

In this study, we described the ongoing research on the dynamics of air pollution in the field of ceramic tile industry. This is a modeling based on system dynamicsthat allows factory and environment managers to discover alternative concepts for industry-specific options used in industry that are looking for proper ways to reduce pollution. As is clear from the model, the most effective variable in reducing air pollution caused by the industry is the lawscorresponding to air pollution. This variable will, in some way,potentially affect other variables, such as the distance from the factory to the city, the quality of the applied raw materials, the quality of the filters used, and the quality of the plant's fuel and transportation vehicles. The effects of this variable indicate that a significant amount of air pollution can be manipulated and mitigated. This model presents a multifaceted assessment of dynamic changes and interacting factors that influence the air pollution. The model can be easily used to reflect the various contexts of environmental organizations and ceramic tile industries. Environmental conditions can be manipulated to allow for systematic analysis.Thus, it can be used as an effective decision support system for organizational and environmental managers. Using the sensitivity analysis of the model,managers can apply the best possible ways to reduce air pollutioncaused by industry.

\section{Acknowledgement}

We would like to appreciate the officials and experts of Yazd Department of Environment, which provided us with the necessary cooperation in collecting the data. Our special thanks also go to Dr. Abolfazl Sadeghian, who contributed in finding the variables and the relationships between them. 


\section{References}

[1] J. C. Trappey, C. Trappey, C. T. Hsiao, J. J. R. Ou, S. J.Li, and K. W. P. Chen, "An evaluation model for low carbonisland policy: The case of Taiwan’s green transportation policy,” Energy Policy, vol. 45, pp. 510-515, Jun. 2012.

[2] Davarpanah, M. \& Davarpanah, M. (2017). Legal review of environmental pollution of soil and climate. Fourth International Conference on Environmental Planning and Management, Tehran, Faculty of Environment, University of Tehran. https://www.civilica.com/Paper-ESPME04-ESPME04_701.html

[3] Fartoukzade, H. \& Rajabi Nahouji, M. (2012). Dynamic modeling of the traffic of metropolises in order to provide transport improvement policies (Case study: Tehran). Journal of Transportation, 9(1), pp. 63-81.

[4] Ismaelzadeh, E., Hamiki, H. A. \& Nabi Farokhi, M. (2004). Designing and implementing a solution for controlling noise pollution caused by thermal power blow-offs. Fourth Iranian National Occupational Health Congress, Hamadan.

[5] Lane, D.C., \& Oliva, R. (1998). The greater whole: Towards a synthesis of system dynamics and soft systems methodology, European Journal of Operational Research, 107, 214-235.

[6] Qiathoddin, M. (????). Air Pollution and Its Effects. In Qiathoddin, M., Comprehensive Health Book. Tehran: Tehran University of Medical Sciences.

[7] Qobadi, Sh. (2009). System dynamics; an application of systemic thinking. Industrial Management Organization Publications.

[8] Riyoufi, S. S., Goharnezhad, H., \& Zakeri Niri, M. (2017). Evaluation of the effects of air pollution on the climate of Tehran using remote evaluation data, Fourth International Conference on Environmental Planning and Management, Tehran, Faculty of Environment, University of Tehran. https://www.civilica.com/Paper-ESPME04-ESPME04_726.html

[9] S. Yu and Y. Wei, "Prediction of China's coal productionenvironmentalpollution based on a hybrid genetic algorithmsystem dynamics model,” Energy Policy, vol. 42, pp. 521-529, Mar. 2012.

[10] Soshil, F. (2007) System dynamics: An applied system approach for managerial issues (Taimouri, E., Nourali, A. R. \& Valizadeh, N., Trans.). Tehran: Science and Technology University Press.

[11] Sterman, J. (????). System dynamics (Shahqolian, K. et al., Trans.). Tehran: Termeh Publications.

[12] Y. Wang, Y. Lin, C.-W. Huang, L.-C. Chiang, H.-J. Chu, andW.-S. Ou, "A System Dynamic Model and Sensitivity Analysis for Simulating Domestic Pollution Removal in a Free-Water Surface Constructed Wetland,” Water, Air, \& Soil Pollution, vol. 223, no. 5, pp. 2719-2742, Jan. 2012.

[13] Yavari, H. \& Saliqeh, M. (2011). Inversion levels in the pollution of Tehran. Journal of Applied Geosciences Research, (17)20. 